\title{
Central cervical fibroid with a typical Lantern on top of St. Paul's cathedral appearance
}

\author{
Ambarisha Bhandiwad, Surakshith L. Gowda*, Anupama N. K., \\ Department of Obstetrics and Gynaecology, JSS Medical College, JSS University, Mysore, Karnataka, India
}

Received: 15 January 2016

Accepted: 08 February 2016

\section{*Correspondence:}

Dr. Surakshith L. Gowda,

E-mail: surakshithlgowda@gmail.com

Copyright: $\odot$ the author(s), publisher and licensee Medip Academy. This is an open-access article distributed under the terms of the Creative Commons Attribution Non-Commercial License, which permits unrestricted non-commercial use, distribution, and reproduction in any medium, provided the original work is properly cited.

\begin{abstract}
Leiomyoma of the uterus in one of the common benign gynecological conditions and one of the rare locations of a fibroid is from the cervix with an incidence of upto $2 \%$. We are reporting a case of a 46 year old patient who came with complaints of mass per abdomen and with a history of retention of urine twice in the past one and half months. Abdominal examination revealed a firm mass of 24 weeks size gravid uterus with restricted mobility arising from the pelvis and a speculum examination, showed a mass protruding through the vagina with all the walls ballooned out and it appeared as if a head of the baby was protruding out in second stage of labor. It was a $1.9 \mathrm{~kg}$ central cervical fibroid with a typical "Lantern on top of St. Paul's cathedral" appearance which was operated without any complications.
\end{abstract}

Keywords: Fibroid uterus, Cervical fibroid, Retention of urine, Mass per abdomen

\section{INTRODUCTION}

Uterine fibroids are benign tumours arising from the smooth muscle cells of the uterus and contain an increased amount of extracellular matrix for which they are also referred as leiomyoma. Incidence of uterine fibroid is $\sim 20 \%$. $^{1.2}$ The paucity of smooth muscles in the cervical stroma makes leiomyomas in the cervix uncommon. Uterine fibroids are known to assume various locations in relation to the uterus and by which they are often classified i.e. submucous, intramural, subserous, pedunculated, interligamentary or parasitic. ${ }^{1}$ They can change the shape of the cervix or may lengthen it. If cervical fibroid grows rapidly, it may push the uterus upwards or obstruct the cervical canal. Without proper anatomical knowledge, large cervical fibroids are difficult to handle.

\section{CASE REPORT}

Mrs. X, 46 year old patient, Para Living $_{2}$ reported to the gynaec OPD with complaints of mass per abdomen for one year and with a history of retention of urine twice in the past one and half months. She had no menstrual irregularities. On examination, general condition of the patient was good. Abdominal examination revealed a firm mass of 24 weeks size gravid uterus with restricted mobility arising from the pelvis. On per speculum examination, a mass seen protruding through the vagina with all the walls ballooned out and it appeared as if a head of the baby was protruding out in second stage of labour and cervix was not visualized. On per vaginal examination, a firm mass of 24 weeks size was made out, cervix not felt and uterus could not be felt separately. USG Abdomen and pelvis showed a large lobulated solid mass in the pelvis one above the other, lower mass measuring $11 \times 10 \mathrm{cms}$ and upper mass measuring $6 \times 6$ cms. On laparotomy, large mass of size $13 * 14 * 10 \mathrm{~cm}$ was seen occupying the pelvis with normal uterus on top with typical appearance of Lantern on top of St. Paul's cathedral.

The whole fibroid along with uterus, bilateral tubes and ovaries were removed in toto. The mass with uterus weighed $1.9 \mathrm{~kg}$ (Figure1). Post operative period was uneventful and patient was discharged in good condition 
on day 7. Histopathological report showed leiomyoma uterus with chronic non - specific cervicitis.

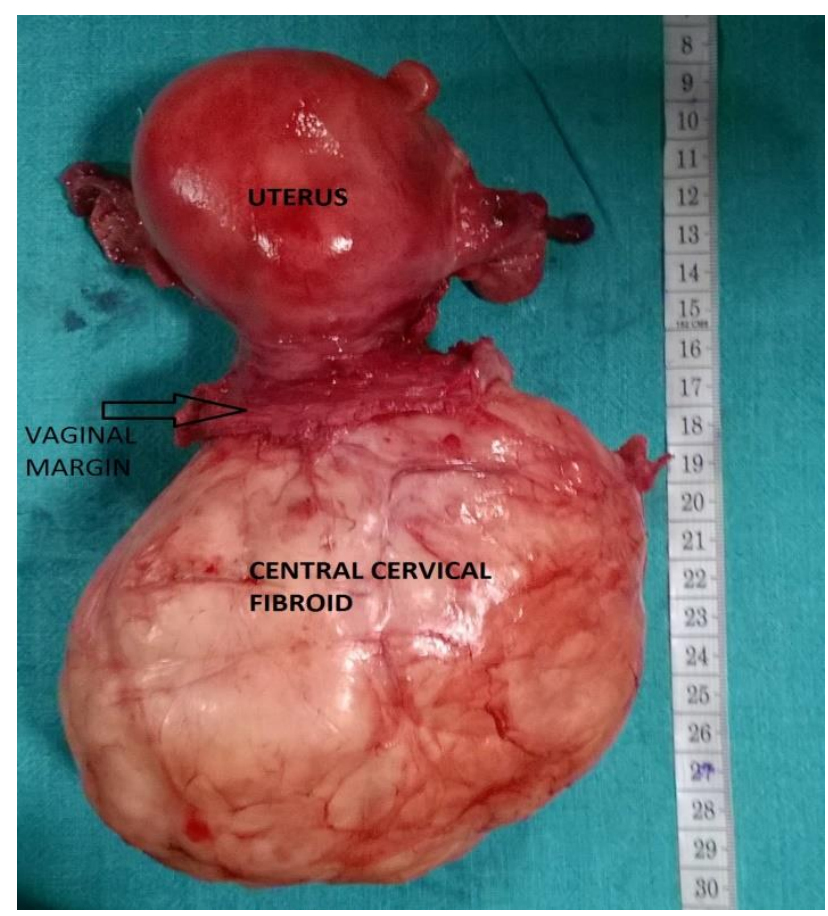

Figure 1: Whole fibroid along with uterus.

\section{DISCUSSION}

The incidence of cervical fibroids is around $0.5 \%$ $2 \% .^{1,2-7}$ Depending on the position, cervical fibroids can be anterior, posterior, lateral or central. ${ }^{1-7}$ Symptoms are mainly due to pressure effects on the bladder leading to acute urinary retention and increased frequency of micturition, the pressure effect on the rectum can cause constipation. ${ }^{3-5}$ Pelvic pain and foul smelling vaginal discharge can be associated with the above mentioned symptoms. ${ }^{3,5}$ Abdominal mass, incarcerated procidentia, sensation of something coming down and in case of pregnancy with cervical fibroid it can cause obstructed labour. ${ }^{2}$

Central cervical fibroid expands the cervix equally in all directions so the pelvic cavity will be completely filled by the tumour. On laparotomy the typical "Lantern on the top of St Paul's cathedral" appearance can be made out as the uterus will be sitting on top of the fibroid. ${ }^{5,6}$

For symptomatic women, the treatment is either hysterectomy or myomectomy and the surgery depends on an accurate assessment of the size, number, and position of fibroids. MRI allows evaluation of the number, size, and position of fibroid and can evaluate their proximity to the bladder, rectum and endometrial cavity. Sonography is the most readily available and least costly imaging technique to differentiate fibroids from other pelvic pathology. ${ }^{3}$ If gonadotropin-releasing hormone $(\mathrm{GnRH})$ analogues are given 3 months prior to surgery, they facilitate by reducing the size and vascularity of fibroids. ${ }^{3,5,7}$ The disadvantage of $\mathrm{GnRH}$ analogue is that they can destroy the fine plane of cleavage between the capsule of the tumour and the surrounding structures.

In case of hysterectomy, the principal to be followed is enucleation followed by hysterectomy to minimize injury to ureter and also uretric stenting can be done prior to surgery. For enucleation in case of central cervical fibroid, the Rotherford Morrison's technique of hemisection of the uterus can also be used. ${ }^{5}$

The problems anticipated during hysterectomy for large cervical fibroid are due to distortion of normal anatomy of ureter and uterine vessels and sometimes due to pulled up bladder anteriorly. Therefore, there are more chances of injury to ureter, bladder and uterine vessels. ${ }^{5,6}$ Intracapsular enucleation of fibroid is the best approach to prevent injury to bladder and ureters. ${ }^{6}$

For enucleation, the capsular incision may be transverse or vertical. The advantage of transverse incision is that it can be placed well above the level of bladder reflection and so reduce the risk of bladder damage. The disadvantage is that it cuts across vessels, which results in increased haemorrhage. The vertical incision can be placed over the most avascular area, usually midline and can be extend into the body of uterus if necessary so as to expose the upper limits of tumor. ${ }^{7}$ The tumor may be impacted in the pelvis displacing the ureters and over hangs the vaginal vault so much that this cannot be reached until the myoma is dislocated upwards or removed by myomectomy. ${ }^{6}$

\section{CONCLUSION}

In case of large cervical fibroids the anatomy will be altered and there are chances for injuring the bladder and ureters as they will be in close proximity to the fibroid. When myomectomy is planned it is always preferred to work within the capsule as it prevents ureteric injuries. A sound anatomical knowledge and proper surgical techniques are essential to prevent complication while operating such cases.

\section{Funding: No funding sources Conflict of interest: None declared Ethical approval: Not required}

\section{REFERENCES}

1. Shinde GR, Khot NKP, Gupta A. Unusual presentation of cervical fibroids: Case report of two cases. International Journal of Recent Trends in Science and Technology. 2015;15(3):515-7.

2. Chaithra TM, Lokeshchandra HC, Bhavani SY. A huge cervical fibroid causing uterovaginal prolapse An unusual presentation, diagnostic dilemma and an 
operative challenge Int $\mathrm{J}$ Med Res Health Sci. 2014;3(3):770-3.

3. Jayashree V, Mahjabeen B, Thariq IA. A case of huge cervical fibroid with characteristic "Lantern on St. Paul's Cathedral" appearance. Indian Journal of Basic and Applied Medical Research. 2015;4,3:4558.

4. SK Geetha, K Saraswathi, S Nirupa. A Rare Case of Impacted Huge Cervical Fibroid Delivered Using a Blade of Obstetric Outlet Forceps. 2015;6(3):14851 .

5. Samal SK, Rathod S, Rajsekaran A, Rani R. An unusual presentation of central cervical fibroid: a case report. Int J Res Med Sci. 2014;2(3):1226-8.
6. Kavitha B, Jyothi R, Rama Devi A, Madhuri K, Sachin Avinash K, SGK Murthy. A rare case of central cervical fibroid with characteristic "Lantern on top of ST.PAUL" appearance. Int J Res Dev Health. 2014;2(1):45-7.

7. Singh S, Chaudhary P. Central cervical fibroid mimicking as chronic uterine inversion: a case report. Int J Reprod Contracept Obstet Gynecol. 2013;2(4):687-8.

Cite this article as: Bhandiwad A, Gowda SL, Anupama NK. Central cervical fibroid with a typical Lantern on top of St. Paul's cathedral appearance. Int J Reprod Contracept Obstet Gynecol 2016;5:924-6. 